\title{
Unusual Presentation of Gastrointestinal Stromal Tumor of Stomach in Neurofibromatosis Type 1: A Case Report
}

\author{
Sudeepta K. Swain • Robinson Smile • Tirou Arul • \\ Dipak David
}

Received: 25 October 2010 / Accepted: 4 June 2012 /Published online: 9 September 2012

(C) Association of Surgeons of India 2012

\begin{abstract}
A 38-year-old woman with generalized neurofibromatosis was admitted to the emergency department with complaint of pain and nontender mass in epigastrium. She had been treated in another hospital as an intra-abdominal abscess and tube drain was seen to be coming out of the centre of the mass. Later investigations and surgery revealed a large exophytic tumor arising from the posterior wall of the stomach infiltrating the transverse colon. Resection of the involved stomach and middle third of the transverse colon was done. Histology examination proved to be leiomyosarcoma positive for CD117 and S-100. Gastrointestinal stromal tumors (GISTs) in neurofibromatosis type 1 (NF1) are multiple and commonly involve the small intestine. This is a rare case of GISTs in NF1 involving the stomach and presenting as an intra-abdominal abscess.
\end{abstract}

Keywords GIST · Stomach · Neurofibromatosis type 1 .

Acute abdomen

\section{Introduction}

Patients with neurofibromatosis type 1 (NF1) have an increased risk of developing gastrointestinal tumors,

Electronic supplementary material The online version of this article (doi:10.1007/s12262-012-0572-y) contains supplementary material, which is available to authorized users.

S. K. Swain $(\triangle) \cdot$ R. Smile $\cdot$ T. Arul $\cdot$ D. David

Department of General Surgery,

Mahatma Gandhi Medical College \& Research Institute,

Pillaiyarkuppam,

Puducherry 607402, India

e-mail: sudeeptapappu@rediffmail.com including rare types such as Gastrointestinal stromal tumor (GIST). GISTs in NF1 patients are usually multiple and found in the small intestine [1]. We report a case of NF1 with GIST of the stomach presenting as an acute abdomen.

\section{Case History}

A 38-year-old female patient having multiple neurofibromatosis, with family history of her mother and sister affected with similar problems (Fig. 1), presented 2 months earlier to another hospital with severe abdominal pain, high fever, and loss of weight. Emergency laparotomy and drainage were carried out with a diagnosis of an intra-abdominal abscess and a tube drain was left in situ. When she presented to our hospital, a firm, nodular nontender mass, size of about $6 \mathrm{~cm} \times 8 \mathrm{~cm}$, was palpable in the left hypochondrium extending to epigastrium and umbilical regions and the drain was seen from the centre of the mass.

Ultrasonography showed fluid collection in the lesser sac suggestive of abscess. CT scan of the abdomen revealed a large mass lesion invading the greater curvature and the posterior wall of the stomach with large necrotic areas within it (Fig. 2). On laparotomy it was a large exophytic tumor arising from the posterior wall of the stomach and infiltrating the middle of transverse colon (Fig. 3). A few enlarged lymph nodes were seen along the greater curvature of the stomach. Resection of the involved stomach and middle third of the transverse colon was done. Postoperative period was uneventful. Investigations were positive for CD117 and S-100. Histology report of the tumor showed leiomyosarcoma infiltrating the transverse colon, and lymph nodes showed no tumor deposit. 


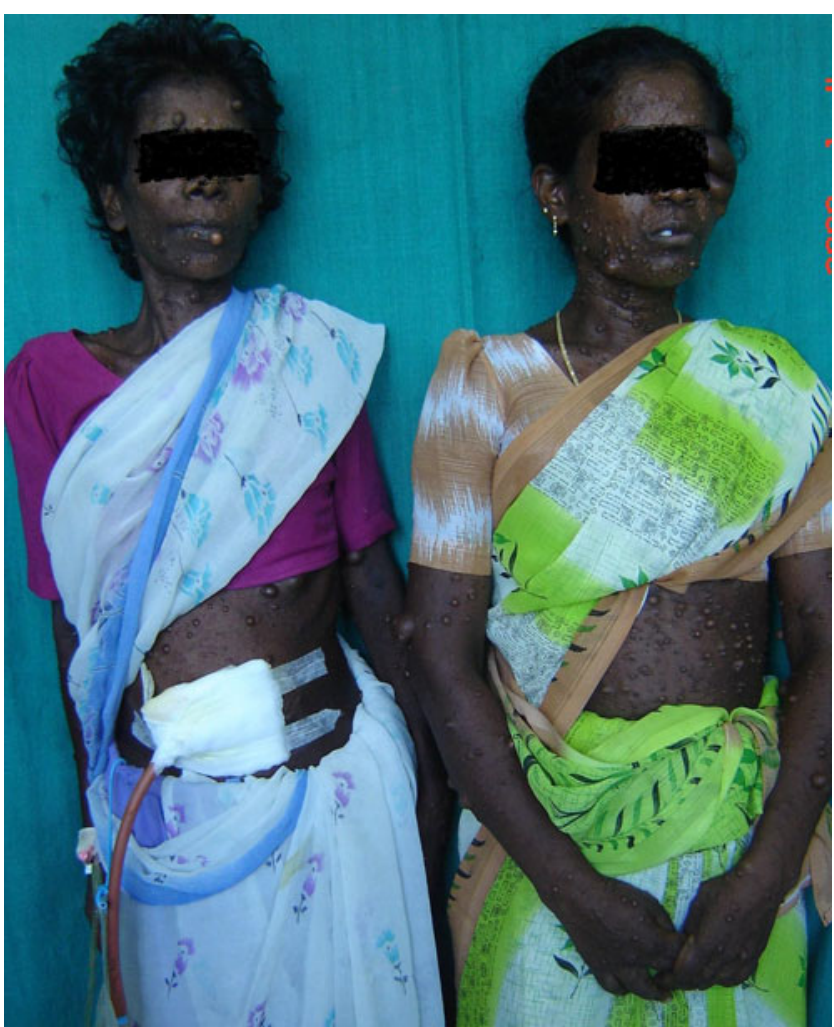

Fig. 1 Patient with her sister on admission

\section{Discussion}

NF1 is a tumor suppressor gene and inactivation of the NF1 gene occurs in about 1 in 3,000 births, and it can be familial with an autosomal inheritance pattern as seen in our patient. Persons affected by NF1 have a much greater probability (7\%) of developing GISTs than general population, and majority of these are found in the small intestine in multiple numbers. In our case, it was a single tumor arising from the stomach.

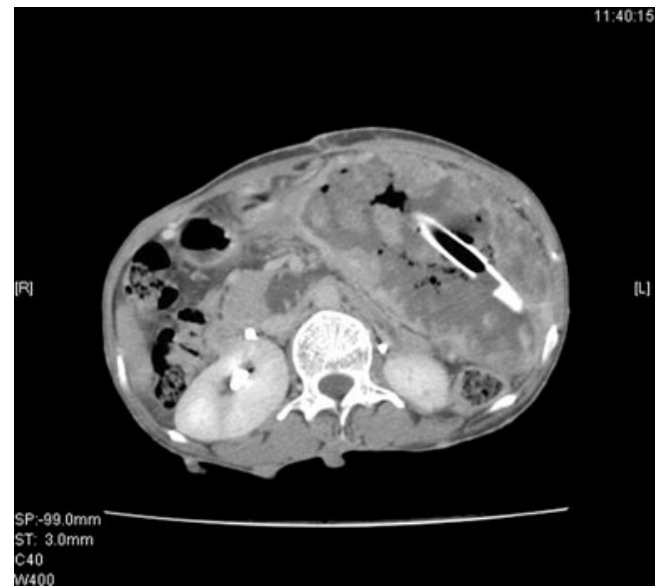

Fig. 2 Contrast CT showing tube drain into the necrotic center of the tumor

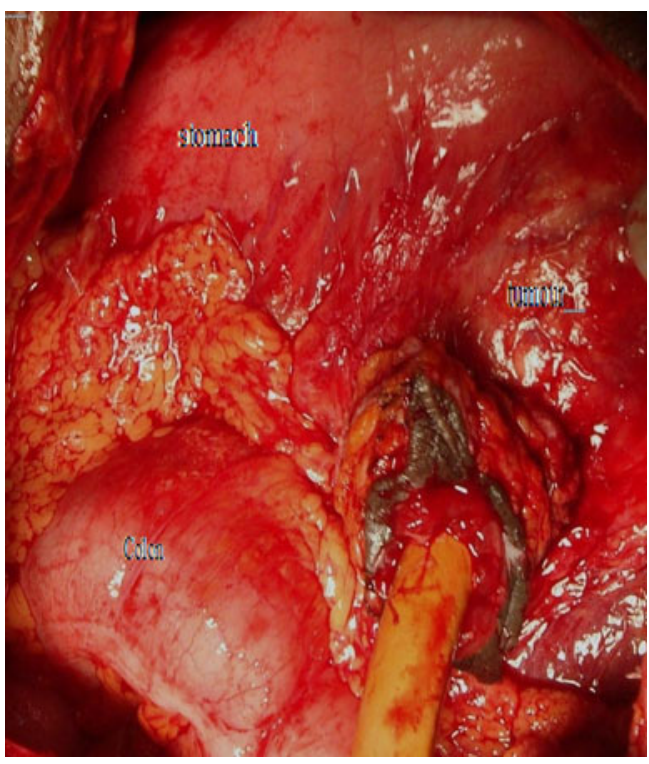

Fig. 3 Laparotomy showing tumor with surrounding organs

The origin of these GISTs may be different because of the lack of identified KIT and PDGFR mutation in patients with NF1 [1]. Miettinen and Lasda reported only one gastric GIST out of 45 patients of GIST associated with NF1 [2]. In a case series of four GISTs from Mumbai, one patient had NF1 with GIST of the duodenum [3].

GIST may be asymptomatic, and if symptomatic they may produce mass effect and are often diagnosed only after resection and histopathological examination. Contrastenhanced CT scan and magnetic resonance imaging are more sensitive in diagnosing GIST. Smaller tumors are usually well circumscribed with neovascularity and larger GISTs can be heterogeneous mass with areas of necrosis and hemorrhage. Metastasis to lungs and lymph nodes is rare. So, lymphadenopathy is rarely seen in imaging studies [4].

Histologically the tumor is highly cellular and composed of spindle-shaped cells that resemble smooth muscle tissue. Confirmation of diagnosis of GIST is done by immunohistochemistry and electron microscopy.

Immunohistochemistry reveals expression of CD117 and other antigens with a positivity of $90-100 \%, \mathrm{CD} 34$ with $70 \%$ positivity. CD117 is a growth factor receptor with a tyrosine kinase activity and is a product of proto-oncogene c-kit. CD117 is expressed in all GISTs and plays an important role in specific diagnostic criteria for GISTs. NF1 GISTs often shows S-100 reactivity, a marker of neural differentiation [5].

Surgical resection remains the mainstay of treatment and offers the only chance for cure [6]. For small gastric tumors, wedge resection is adequate, and larger tumors necessitate subtotal or total gastrectomy as in our patient [7]. Despite the proven success of Imatinib and other newer tyrosine kinase inhibitors, $50-70 \%$ of GISTs have partial response to these [8]. 


\section{References}

1. Kingham P, DeMatteo RP (2009) Multidisciplinary treatment of gastrointestinal stromal tumours. Surg Clin North Am 89:217233

2. Miettinen M, Lasda J (2006) Gastrointestinal tumours, review on morphology, molecular pathology, prognosis and differential diagnosis. Arch Pathol Lab Med 130:1466-1478

3. Kanthalia CV, Prabbu RY et al (2008) Presentation of gastrointestinal stromal tumours. Ind J Surg 70:318-321

4. Miettinen M, Sobin LH, Lasota J (2005) Gastrointestinal stromal tumours of the stomach: a clinicopathologic, immunohistochemical and molecular genetic study of 1765 cases with long term follow up. Am J Surg Pathol 29(1):52-68

5. Tkazawaa Y, Sakurai S, Sakuma Y, Ikeda T, Yamaguchi J (2005) Gastro-intestinal stromal tumours of neurofibromatosis type 1. Am J Surg Pathol 29(6):755-763

6. Ng EH, Pollock RE, Munsell MF et al (1992) Prognostic factors influencing survival in gastrointestinal leiomyosarcomas: implications for surgical management and staging. Ann Surg 215:6877
7. Dematteo RP, Lewis JJ, Leung D et al (2000) Two hundred gastrointestinal stromal tumours, recurrence patterns and prognostic factors for survival. Ann Surg 231(1):51-58

8. Verweij J, Casali PG, Zalcberg J et al (2004) Progression free survival in gastrointestinal stromal tumours with high dose imatinib a randomised trial. Lancet 364(9440):1127-1134

\section{Few previous publications by authors}

1. Gastric carcinoid - A case report. Ind J Surgery1991;53:322-324.

2. Solitary intrahepatic choledochal cyst. Ind J Surgery 1993; 55: 294.

3. Morbidity and mortality of definitive surgical procedure in Duodenal ulcer perforation. Ind J Surgery 1994;56:102.

4. Malignant granular cell tumour - A case report and review of Literature. Ind J Cancer 1992; 29:31-33.

5. Colostomy closure and wound infection; Evaluation of risk factors. Ind J Surgery 1997;59:211-214.

6. Delay in surgery for acute appendicitis. ANZ J Surgery2004;74:9.

7. Treatment of anal fissure using a combination of minoxidil and Lignocaine a randomized double blind trial. Ind J GE 2005;24:158. 